\title{
The pathological basis of conduction block in human neuropathies
}

\author{
TE FEASBY, ${ }^{*}$ WF BROWN,${ }^{*}$ JJ GILBERT, $\dagger$ AF HAHN* \\ From the Departments of Clinical Neurological Sciences* and Pathology, $\dagger$ University and Victoria Hospitals \\ and the University of Western Ontario, London, Ontario, Canada
}

SUMMARY Conduction block was detected in patients with neuropathy by measuring a decrease in the size of the compound muscle action potential of more than $20 \%$ on proximal versus distal stimulation of the peroneal, median or ulnar nerve in the absence of excess temporal dispersion of the potential. The teased fibre analyses of nerve biopsies from four patients with "definite" and six patients with "probable" conduction block and from seven patients with neuropathy but without conduction block were compared. All patients with conduction block had significant demyelination ( $\overline{\mathrm{X}} \%$ demyelinated and remyelinated fibres $=50 \%$ ) while those without conduction block did not $(\overline{\mathrm{X}}=5.0 \%)$. Demyelination is the pathological basis of conduction block in human neuropathies.

Conduction block, the arrest of transmission of action potentials in intact axons, is one of the most important physiological consequences of experimental demyelination. ${ }^{2}$ While the clinical importance of conduction block has been noted previously, ${ }^{3-5}$ only recently have systematic sudies of conduction block been made in human neuropathies. ${ }^{6-10}$ This study examines the pathological basis of conduction block in human neuropathies.

\section{Methods}

\section{A Patients}

The electrophysiological studies of patients who had nerve biopsies were reviewed, excluding those with familial neuropathies. Those patients whose clinical electrophysiological studies showed evidence of conduction block were placed in group I $(n=10)$, while those without evidence of conduction block were placed in group II $(\mathbf{n}=$ 7) with the object of looking for significant distinctions between the morphological characteristics of the nerve fibres in the two groups. The patients in group I all had generalised symmetrical sensorimotor polyneuropathy. Eight patients had chronic progressive demyelinating neuropathy, one had chronic relapsing demyelinating

Address for reprint requests: Dr TE Feasby, Department of Clinical Neurological Sciences, University Hospital, 339 Windermere Road, London, Ontario, Canada, N6A 5A5.

Received 25 May 1984 and in revised form 31 July 1984. Accepted 6 August 1984 neuropathy and one had acute Guillain-Barré polyneuropathy (table). None had the multifocal form of chronic progressive demyelinating neuropathy. ${ }^{9}$ Biopsies in all patients but one (CB) were done prior to treatment, when the clinical deficits were severe. All those in group II were found to have "axonal" neuropathies.

\section{B Electrophysiological studies}

Maximum motor conduction velocities were determined for the peroneal, ulnar and median nerves using conventional techniques. ${ }^{6}$

Conduction block was assessed by measuring and comparing the peak-to-peak (p-p) amplitudes, negative peak $(-p)$ and $p-p$ durations and the $-p$ areas of the maximum " $M$ " potentials elicited by percutaneous supramaximal stimulation of a motor nerve at two sites, one within 50$100 \mathrm{~mm}$ of the motor point and the other $200 \mathrm{~mm}$ or more proximal to the distal stimulus site (fig 1). These two sites were the wrist and elbow in the case of the median and ulnar nerves and ankle and fibular head in the case of the peroneal nerve. The recordings in each case were made with surface electrodes, the stigmatic electrode of which was positioned over the innervation zone for the respective hypothenar, thenar and extensor digitorum brevis (EDB) muscles. Negative peak areas were measured using a digitizer.

Our criteria for definite conduction block included: (1) a greater than $20 \%$ reduction in the p-p amplitude, and (2) an increase in the $-p$ duration of no more than $15 \%$ of the maximum " $M$ " potential elicited by stimulation at the proximal site compared to that evoked by distal stimulation.

In cases where there was a greater than $15 \%$ increase in 
Table Patients with "Definite" and "Probable" Conduction Block

\begin{tabular}{|c|c|c|c|c|c|c|c|c|c|c|c|c|c|c|c|c|c|c|}
\hline \multicolumn{7}{|c|}{ Physiology } & \multicolumn{12}{|c|}{ Teased fibres } \\
\hline$P t$ & Nerve & $\begin{array}{l}\text { \% change in } \\
-p \text { area }\end{array}$ & $\begin{array}{l}\text { \% change } \\
p-p \text { amplitude }\end{array}$ & $\begin{array}{l}\% \text { change in } \\
-p \text { duration }\end{array}$ & $M T L$ & $\overline{C V}$ & Nerve & $A+B$ & $C$ & $D$ & $E$ & $F$ & $G$ & $H$ & $I$ & $C+D+F$ & $n=$ & $\begin{array}{l}\text { Cliniç्र } \\
\text { diagnasis }\end{array}$ \\
\hline $\begin{array}{l}\text { RH } \\
\text { RK } \\
\text { CB } \\
\text { WA }\end{array}$ & $\begin{array}{l}\mathbf{U} \\
\mathbf{P} \\
\mathbf{P} \\
\mathbf{U}\end{array}$ & $\begin{array}{l}-65 \\
-62 \\
-47 \\
-27\end{array}$ & $\begin{array}{l}-80 \\
-37 \\
-47 \\
-31\end{array}$ & $\begin{array}{l}+15 \\
+13 \\
+8 \\
+13\end{array}$ & $\begin{array}{l}5 \cdot 4 \\
4 \cdot 2 \\
5 \cdot 7 \\
4 \cdot 0\end{array}$ & $\begin{array}{l}29 \\
38 \\
38 \\
52\end{array}$ & $\begin{array}{l}\text { DP } \\
\text { S } \\
\text { DP } \\
\text { DP }\end{array}$ & $\begin{array}{l}50 \\
72 \\
77 \\
48\end{array}$ & $\begin{array}{r}6 \\
19 \\
4 \\
5\end{array}$ & $\begin{array}{r}33 \\
4 \\
2 \\
35\end{array}$ & $\begin{array}{l}9 \\
0 \\
1 \\
5\end{array}$ & $\begin{array}{r}2 \\
5 \\
16 \\
5\end{array}$ & $\begin{array}{l}0 \\
0 \\
0 \\
2\end{array}$ & $\begin{array}{l}0 \\
0 \\
0 \\
0\end{array}$ & $\begin{array}{l}0 \\
0 \\
0 \\
0\end{array}$ & $\begin{array}{l}41 \\
28 \\
22 \\
45\end{array}$ & $\begin{array}{l}138 \\
149 \\
117 \\
124\end{array}$ & $\begin{array}{l}\text { CPDP } \\
\text { GBP } \\
\text { CPDP } \\
\text { CPDP } \\
\end{array}$ \\
\hline $\begin{array}{l}\mathrm{JE} \\
\mathrm{JV} \\
\mathrm{DK} \\
\mathrm{MT} \\
\mathrm{PT} \\
\mathrm{WZ}\end{array}$ & $\begin{array}{l}\mathbf{M} \\
\mathbf{M} \\
\mathbf{U} \\
\mathbf{U} \\
\mathbf{M} \\
\mathbf{U}\end{array}$ & $\begin{array}{l}-75 \\
-63 \\
-57 \\
-66 \\
-65 \\
-59\end{array}$ & $\begin{array}{l}-71 \\
-62 \\
-66 \\
-65 \\
-82 \\
-61\end{array}$ & $\begin{array}{l}+75 \\
+31 \\
+52 \\
+35 \\
+32 \\
+38\end{array}$ & $\begin{array}{r}8 \cdot 1 \\
9 \cdot 4 \\
21 \cdot 0 \\
17 \cdot 0 \\
3 \cdot 8 \\
6 \cdot 5\end{array}$ & $\begin{array}{r}12 \\
16 \\
5 \\
14 \\
25 \\
20\end{array}$ & $\begin{array}{l}\text { DP } \\
\text { DP } \\
\text { DP } \\
\text { DP } \\
\text { DP } \\
\text { DP }\end{array}$ & $\begin{array}{l}52 \\
18 \\
19 \\
46 \\
53 \\
20\end{array}$ & $\begin{array}{r}15 \\
16 \\
7 \\
5 \\
15 \\
5\end{array}$ & $\begin{array}{r}11 \\
58 \\
70 \\
11 \\
1 \\
58\end{array}$ & $\begin{array}{l}9 \\
3 \\
1 \\
2 \\
5 \\
5\end{array}$ & $\begin{array}{r}12 \\
5 \\
3 \\
36 \\
26 \\
12\end{array}$ & $\begin{array}{l}1 \\
0 \\
0 \\
0 \\
0 \\
0\end{array}$ & $\begin{array}{l}0 \\
0 \\
0 \\
0 \\
0 \\
0\end{array}$ & $\begin{array}{l}0 \\
0 \\
0 \\
0 \\
0 \\
0\end{array}$ & $\begin{array}{l}38 \\
79 \\
80 \\
52 \\
42 \\
75\end{array}$ & $\begin{array}{l}105 \\
103 \\
106 \\
106 \\
102 \\
109\end{array}$ & $\begin{array}{l}\text { CPDP } \\
\text { CPDP. } \\
\text { CRDP } \\
\text { CPDP } \\
\text { CPDP } \\
\text { CPDP }\end{array}$ \\
\hline$\overline{\mathbf{x}}=$ & & -59 & -60 & & & & $\overline{\mathbf{x}}=$ & 46 & 10 & 28 & 4 & 12 & & & & 50 & & $\overline{\bar{\omega}}$ \\
\hline
\end{tabular}

In control patients $(n=7)$ the biopsies showed $5 \%(\overline{\mathrm{x}})$ demyelinated fibres $(C+D+F)$ and $9 \%$ fibres (E) with Wallerian degeneration. $U-u l\left(\mathbb{R}_{a r}\right.$, $\mathrm{M}-$ median, P-peroneal, DP-deep peroneal, S-sural, GBP-Guillain-Barré polyneuropathy, CPDP-chronic progressive demyelinating pQIyneuropathy, CRDP-chronic relapsing demyelinating polyneuropathy, MTL-motor terminal latency (milliseconds), CV-conduction velocity (metoes/ second).

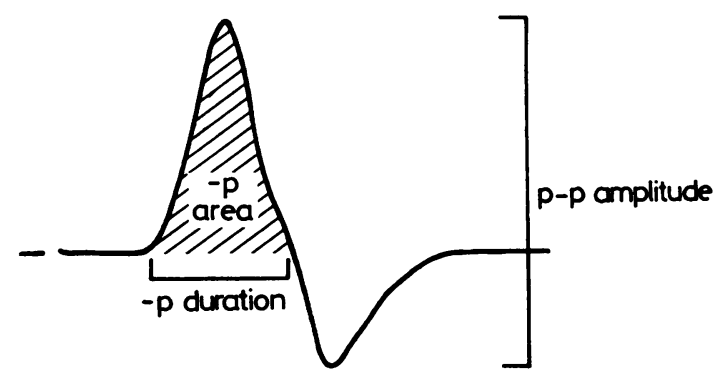

Fig 1 Measurement of the peak-to-peak (p-p) amplitude and negative peak (-p) duration and $-p$ area of the maximum compound muscle action potential.

the - $p$ duration elicited at the more proximal of the two stimulus sites (temporal dispersion), conduction block was considered probable provided the reduction in $\mathrm{p}-\mathrm{p}$ amplitude exceeded $30 \%$ and was paralleled by a like reduction in $-p$ area.

For the best correlation between morphological changes and the conduction studies, the peroneal nerve was preferred. Unfortunately, in most cases, such a direct comparison of biopsy and physiological studies in the peroneal nerve was not feasible because too few extensor digitorum brevis motor units were excitable at the ankle $(<5$ motor axons using the incremental stimulation technique) to make a meaningful assessment of conduction block between the fibular head and ankle stimulus site possible. However, the physiological findings in these cases were those of generalised symmetrical polyneuropathy and conduction block was usually found in several nerves, suggesting that the peroneal nerve would provide a reasonably representative sample of the underlying morphological abnormalities.

\section{Histological studies}

Nine patients had a combined biopsy of the superficial peroneal nerve and the lateral fascicles of the deep peroneal nerve. One patient (RK) had a sural nerve biopsy. The patients in group II all had deep and superficial peroneal nerve biopsies. The nerves were fixed in glutaraldehyde, processed and embedded in epon for light and electron microscopy. A portion of each specimen was also teased either in glycerin or in unpolymerised epon. At least 100 myelinated fibres were teased and graded according to Dyck." Fibre categories C (paranodal demyelination), D (segmental demyelination) and $\mathrm{F}$ (remyelination) were totalled to provide an overall index of demyelination.

\section{Results}

Four patients fulfilled the criteria for "definite" conduction block in at least one motor nerve (fig 2 and table). In three of four cases the reductions in - $p$ area paralleled the reduction in $p-p$ amplitude. In six patients the increase in $-p$ duration between the proximal and distal stimulus sites exceeded $15 \%$, indicating a greater than normal degree of temporal dispersion (fig 3 and table). These increases in $\cdot p$ duration were, however, accompanied by a greater than $30 \%$ reduction in the p-p amplitude of the maximum " $M$ " potential and as a consequence were taken to indicate that conduction block was probably present. In five of these six cases the amplitude reductions were accompanied by closely matching reductions in the $-p$ area of the maximum " $M$ " potentials between the two stimulus sites. In these cases, clinical recovery after treatment was paralleled by recovery from conduction block. One example is shown (patient JE, fig 3), where neurophysiological testing at a later date, revealed a remarkable reversal of the "probable" conduction block seen at the time of the initial study.

All the nerve biopsies of those patients considered to have "definite" or "probable" conduction block 

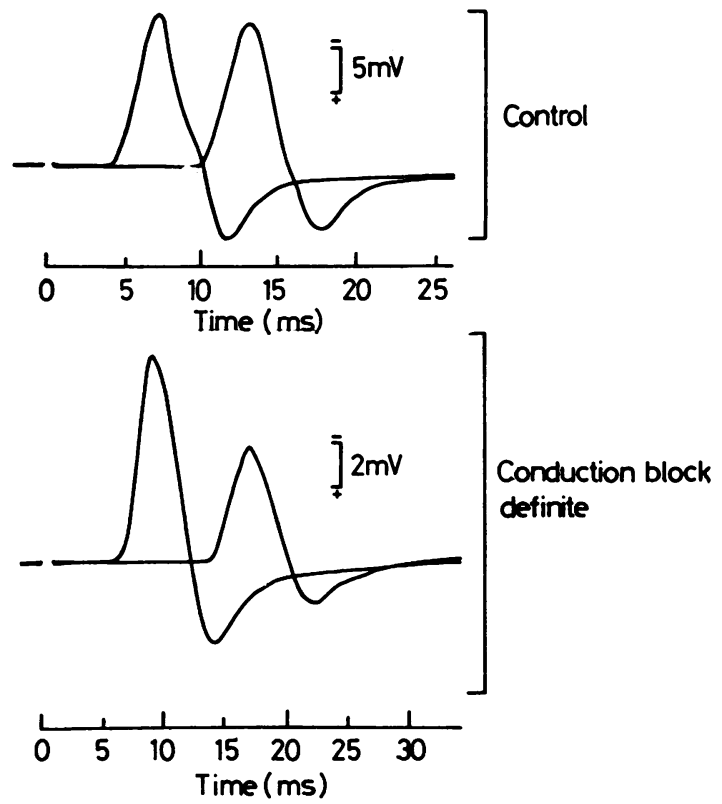

Fig 2 Surface recordings from the extensor digitorum brevis muscle with stimulation of the common peroneal nerve at the ankle and the fibular head. The lower recording showing "definite" conduction block is from patient $C B$ (see case report).
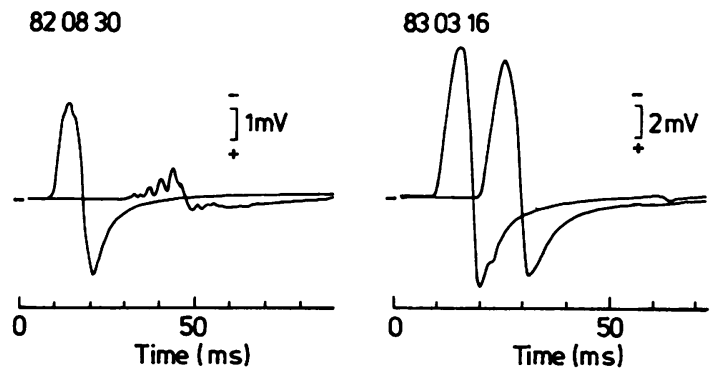

Fig 3 Recordings from the hypothenar muscles (ulnar nerve) of patient JE who had chronic progressive demyelinating polyneuropathy. On 30 August 1982, "probable" conduction block was present and he had generalised weakness. On 16 March 1983, after clinical recovery, the potential evoked by stimulation at the elbow had increased markedly indicating that the conduction block had disappeared.

showed abundant evidence of demyelination $(\overline{\mathrm{x}}=$ $34 \%$ and $61 \%$ in the respective "definite" and "probable" conduction block groups, $[C+D+F$ fibres inclusive]) accompanied by lesser degrees of axonal degeneration $(\bar{x}=4 \%)$. The magnitude of the reduction in " $M$ ' potential size between the two stimulus sites did not, however, correlate significantly with the proportion of teased fibres showing demyelination or with the percentages of $C$, $\mathrm{D}$ or $\mathrm{F}$ fibres taken individually.

In those patients, without electrophysiological evidence of conduction block, (Group II), demyelination was infrequent ( $\bar{x}=5 \%, C+D+F$ fibres) and axonal degeneration was more common $(\overline{\mathrm{x}}=$ 9\%, E fibres).

\section{Case report}

A 33-year old man (CB) first complained of tingling in his fingers in November 1978. This was followed by a gradually progressive quadriparesis. Treatment with prednisone produced only transient improvement and although his condition improved with plasmapheresis, recurrent phlebitis and pulmonary emboli precluded further exchanges. On azathioprine $200 \mathrm{mg}$ twice daily and prednisone $25 \mathrm{mg}$ on alternate days he remained reasonably stable.

Examination in April 1982 showed mild wasting of forearm and hand muscles, fasciculations in both quadriceps and mild weakness in all limb muscles except his shoulder girdle. A fine postural and intention tremor was seen in both hands. Pin prick, vibration and position sense were minimally reduced in his great toes. His tendon jerks were $1+$ throughout. The peripheral nerves were not palpably enlarged.

Needle EMG showed occasional enlarged motor unit potentials (increased duration and amplitude) in the tibialis anterior, extensor digitorum brevis and longus and gastrocnemius muscles. Motor and sensory conduction velocities were within the 2 SD lower limits established for control subjects in the ulnar and median nerves. As well, the amplitudes of the sensory nerve action potentials and the maximum sensory conduction velocities from the sural and superficial peroneal nerves were within the 2 SD limits of controls. The maximum motor conduction velocity in the right peroneal nerve was mildly reduced $(38 \mathrm{~m} / \mathrm{s}$; normal $>40.0$ ) and the motor terminal latency slightly prolonged $(5 \cdot 7 \mathrm{~m} / \mathrm{s}$; normal $<5.0)$.

The most significant physiological abnormality seen was conduction block (fig 2 ). The amplitude and $-p$ area of the extensor digitorum brevis maximum " $\mathbf{M}$ " potential elicited by supramaximal stimulation of the peroneal nerve at the fibular head were both reduced by $47 \%$ compared to those from stimulation at the ankle. These findings and the fact that the duration of the negative peak of the "M" potential was increased by less than $15 \%$, were taken to indicate that conduction block was definitely present.

The deep peroneal nerve biopsied just proximal to the ankle showed a normal density of myelinated fibres $\left(7,396 / \mathrm{mm}^{2}\right)$ and a normal myelinated fibre size range. Occasional thinly myelinated fibres were observed in cross section. However, examination of teased fibres (table) disclosed a high proportion (22\%) of demyelinated and remyelinated fibres. This confirmed the diagnosis of chronic demyelinating neuropathy and correlated with the physiological finding of conduction block despite the relative normality of the motor and sensory conduction velocities and the amplitudes of the sensory potentials. 


\section{Discussion}

Of the several functional consequences of demyelination known to occur in human and experimental demyelinating neuropathies, ' conduction block must certainly rank as one of the most important causes of clinical deficits. Slowing of conduction and the associated desynchronisation of transmission of impulses in motor axons would not by themselves be expected to result in weakness. Indeed, severe slowing of conduction velocity is quite compatible with the maintenance of good strength as shown by studies of families with hereditary motor sensory neuropathy, type $1 .^{12}$ However, temporal dispersion probably does contribute to some non-disabling features of demyelinating neuropathies such as areflexia and lost vibration sense. ${ }^{13}$

Despite its importance, conduction block, until recently, has received relatively little attention in studies of human demyelinating neuropathies, possibly because of the difficulties faced by the clinical electrophysiologist in its assessment. One of the chief technical difficulties is that, as recorded extracellularly in volume, the component motor unit potentials are necessarily tri-or biphasic. Hence, any appreciable differences in the timing of the discharges of the component motor unit potentials (MUPs) such that opposite phases of different MUPs overlap, will necessarily result in some reduction in the size (amplitude and area) of the compound action potential. The magnitude of such phase cancellations will depend, among other factors, on the differences in the conduction velocities of the component MUPs and the distance proximal to the motor point at which the nerve was electrically stimulated. In normal human motor nerves there is little reduction in the maximum " $M$ " potential p-p amplitude or - $p$ area even over appreciable conduction distances of $400-600 \mathrm{~mm} .6$ In addition, computer simulation studies strongly suggest that the maximum " $M$ " potential is dominated by the numerically small group of large motor units with fast-conducting axons (Brown and Yates, unpublished). Such simulation studies suggest that conduction block in appreciable numbers of axons to small motor units has little impact on the size of the " $M$ " potential, whereas block in a similar number of the faster conducting fibres generating the larger MUPs produces a relatively much larger reduction in the size of the maximum " $M$ " potential.

The preceding factors, namely the types of motor axons affected, the conduction distance and differences in the conduction velocities of the motor axons whose impulses remained unblocked, should all combine to make the electrophysiologist cautious in ascribing reduction in " $M$ " potential size as the stimulus site is moved proximally to conduction block.

The assessment of conduction block is the most complicated when differences in the conduction velocities of motor axons increase to the point where temporal dispersion becomes evident as an appreciable increase in " $M$ " potential duration $(-p)$ and desynchronisation of the potential itself. In this case, part of the reduction in " $M$ " potential size on proximal stimulation could be a result of enhanced phase cancellation between individual MUPs. For this reason, we considered that conduction block was "probable", not "definite", when the reduction in " $M$ " potential amplitude (p-p) and especially area $(-p)$ exceeded $30 \%$. The latter value in our computer simulation studies was found to be a reasonable limit in the face of increased temporal dispersion.

In this series of cases where conduction block was present, four patients were considered to have "definite" conduction block while in six, excessive temporal dispersion precluded such a conclusion. In all six, however, conduction block was thought to be "probable" based on the magnitude of the reduction in " $M$ " potential size between the stimulus sites and clinical improvement in all was accompanied by reversal of the "probable" conduction block (fig 3 ).

Despite the reasonable correlation shown in this study between the occurrence of demyelination and the finding of conduction block in human neuropathies, these studies are not able to define further the precise extent and character of the lesions actually responsible for the conduction block. Indeed, precise correlation between the? degree of conduction block and the teased fibre measurement of demyelination would have been surprising in this study for several reasons. For example, the physiological studies assessed alpha motor nerve fibres only, while the nerve fibres included in the teased preparations included gamma motor fibres and sensory fibres as well. Furthermore, the biopsies and the physiological studies were often carried out on different nerves and sometimes several days apart. Thus, while physiological studies $^{14}$ is and computer simulations of single fibre conduction ${ }^{161718}$ have been able to identify some specific factors favouring conduction block, this was not possible in a study such as ours.

Parallel anatomical and physiological studies of experimental neuropathies have identified the relationship between conduction block and demyelination. Denny-Brown and Brenner ${ }^{19}$ produced conduction block by experimental nerve compression and provided evidence that the underlying pathology was demyelination. More detailed anatomical studies of compressed baboon nerves have shown that nerve compression produces a specific "intus- 
suseption" of the myelin sheath resulting in paranodal demyelination. ${ }^{20}$ Pathophysiological studies of experimental diphtheritic neuritis and experimental allergic neuritis, two demyelinating neuropathies, provided convincing evidence of the connection between demyelination and conduction block. ${ }^{21-23}$ Physiological studies of single nerve fibres undergoing demyelination ${ }^{1524}$ indicated that the loss of myelin produced an increase in internodal capacitance and consequently a reduction of trans-nodal membrane current resulting in conduction block.

The clinical importance of conduction block in human neuropathies is still being defined. Seddon, ${ }^{25}$ in his classification of human nerve injuries, used the term neurapraxia for lesions with the "clinical" characteristics of conduction block. Conduction block was subsequently found to be a prominent and long-lasting feature of such focal nerve injuries as tourniquet paralysis. ${ }^{26} 27$ Other focal "compressive" neuropathies such as carpal tunnel syndrome, ${ }^{28} 29$ "Saturday night palsy"' (radial nerve) ${ }^{30}$ and various ulnar neuropathies ${ }^{3132}$ may also be characterised by conduction block. Although it was recognised over 20 years ago that conduction block was an important feature of Guillain-Barré polyneuropathy, ${ }^{45}$ it has received little attention until recently. Brown and Feasby ${ }^{6}$ have shown that conduction block occurs in the acute phase of Guillain-Barré polyneuropathy in most patients and is the major cause of acute neurological disability. Lewis et $\mathbf{l}^{9}$ found multifocal conduction block in a form of multifocal chronic acquired demyelinating neuropathy. Lewis and Sumner ${ }^{10}$ studying chronic demyelinating neuropathies, showed that conduction block often occurred in the acquired but not in the hereditary types. Kelly ${ }^{8}$ found conduction block in some cases of neuropathy associated with monoclonal gammopathy. Based on our studies and the pathological data available on these focal and polyneuropathies, we conclude that as in the experimental models, demyelination is the pathological basis of conduction block in human neuropathies.

We thank D Malott, SK Yates and E Leslie for excellent assistance.

\section{References}

' McDonald WI. Physiological consequences of demyelination. In: Sumner AJ, ed. The Physiology of Peripheral Nerve Disease. Philadelphia: WB Saunders, 1982:265-86.

${ }^{2}$ Sears TA, Bostock H. Conduction failure in demyelination: is it inevitable? In: Waxman SG, Ritchie JE, eds. Demyelinating Diseases. Basis and Clinical Electrophysiology. New York: Raven Press, 1981:357-76.
${ }^{3}$ Austin JH. Recurrent polyneuropathies and their corticosteroid treatment. With five-year observations of a placebo-controlled case treated with corticotrophin, cortisone and prednisone. Brain 1958;81:157-92.

${ }^{4}$ Bannister RG, Sears TA. The changes in nerve conduction in acute idiopathic polyneuritis. $J$ Neurol Neurosurg Psychiatry 1962;25:321-8.

${ }^{5}$ Lambert EH. Neurophysiological techniques useful in the study of neuromuscular disorders. Research Publications-Association for Research in Nervous and Mental Disease (Baltimore) 1961;38:247-73.

- Brown WF, Feasby TE. Conduction block and denervation in Guillain-Barré polyneuropathy. Brain 1984; 107:219-39.

${ }^{7}$ Brown WF, Feasby TE, Gilbert JJ, et al. Conduction block and denervation in Guillain-Barré polyneuritis. Trans Am Neurol Assoc 1981;106:168-72.

${ }^{8}$ Kelly JJ. The electrodiagnostic findings in peripheral neuropathy associated with monoclonal gammopathy. Muscle Nerve 1983;6:504-9.

${ }^{9}$ Lewis RA, Sumner AJ, Brown MJ, Asbury AK. Multifocal demyelinating neuropathy with persistent conduction block. Neurology (NY) 1982;32:958-64.

${ }^{10}$ Lewis RA, Sumner AJ. The electrodiagnostic distinctions between chronic familial and acquired demyelinative neuropathies. Neurology (NY) 1982;32:592-6.

"Dyck PJ. Pathologic alterations of the peripheral nervous system of man. In: Dyck PJ, Thomas PK, Lambert EH, eds. Peripheral Neuropathy. Philadelphia: WB Saunders, 1975:296-336.

12 Dyck PJ, Lambert EH. Lower motor and primary sensory neuron diseases with peroneal muscular atrophy. I. Neurologic, genetic and electrophysiologic findings in hereditary polyneuropathies. Arch Neurol 1968; 18:603-18.

${ }^{13}$ Gilliatt RW, Willison RG. Peripheral nerve conduction in diabetic neuropathy. $J$ Neurol Neurosurg Psychiatry 1962;25: 11-8.

${ }^{14}$ Bostock H, Sears TA. The internodal axon membrane: electrical excitability and continuous conduction in segmental demyelination. J Physiol (Lond) 1978;280:273-301.

is Lafontaine S, Rasminsky M, Saida T, Sumner A. Conduction block in rat myelinated fibres following acute exposure to anti-galactocerebroside serum. J Physiol (Lond) 1982;323:287-306.

${ }^{16}$ Koles ZJ, Rasminsky M. A computer simulation of conduction in demyelinated nerve fibres. J Physiol (Lond) 1972;227:351-64.

${ }^{17}$ Moore JW, Joyner RW, Brill MH, Waxman SD, NajarJoa M. Simulations of conduction in uniform myelinated fibres: relative sensitivity to changes in nodal and internodal parameters. Biophys $J$ 1978;21:14760.

18 Waxman SG, Brill MH. Conduction through demyelinated plaques in multiple sclerosis: computer simulations of facilitation by short internodes. $J$ Neurol Neurosurg Psychiatry 1978;41:408-16.

19 Denny-Brown D, Brenner C. Paralysis of nerve induced by direct pressure and by tourniquet. Arch Neurol Psychiat 1944;51:1-26. 
${ }^{20}$ Ochoa J, Fowler TJ, Gilliatt RW. Anatomical changes in peripheral nerves compressed by a pneumatic tourniquet. J Anat 1972;113:433-55.

${ }^{21}$ Cragg BG, Thomas PK. Changes in nerve conduction in experimental allergic neuritis. J Neurol Neurosurg Psychiatry 1964;27:106-15.

${ }^{22}$ Kaeser HG, Lambert EH. Nerve function studies in experimental polyneuritis. Electroencephalogn Clin Neurophysiol (suppl) 1962;22:29-35.

${ }^{23}$ McDonald WI. The effects of experimental demyelination on conduction in peripheral nerve: a histological and electrophysiological study. II Electrophysiological Observations 1963;86:501-24.

${ }^{24}$ Tasaki I. New measurements of the capacity and the resistance of the myelin sheath and the nodal membrane of the isolated frog nerve fibre. Am J Physiol 1955;181:639-50.

${ }^{25}$ Seddon HJ. Three types of nerve injury. Brain 1943;66: 238-88.

${ }^{26}$ Bolton CF, McFarlane RM. Human pneumatic tourni- quet paralysis. Neurology (Minneap) 1978;28:78793.

${ }^{27}$ Rudge P. Tourniquet paralysis with prolonged conduction block. J Bone Joint Surg 1974;56B:716-20.

${ }^{28}$ Brown WF, Ferguson GG, Jones MW, Yates SK. The location of conduction abnormalities in human extrapment neuropathies. Can J Neurol Sci 1979; 3:111-22.

${ }^{29}$ Hongell A, Mattson HS. Neurographic studies before, after, and during operation for median nerve compression in the carpal tunnel. Scand J Plast Reconstr Surg 1971;5:103-9.

${ }^{30}$ Trojaborg W. Prolonged conduction block with axonal degeneration. An electrophysiological study. J Neurol Neurosurg Psychiatry 1977;40:50-7.

${ }^{31}$ Harrison MJG. Pressure palsy of the ulnar nerve with prolonged conduction block. J Neurol Neurosurg Psychiatry 1976;36:96-9.

${ }^{32}$ Miller RG, Olney RK. Persistent conduction block in compression neuropathy. Muscle Nerve 1982;5: S154-6. 